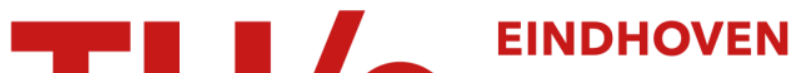 \\ UNIVERSITY OF \\ TECHNOLOGY
}

\section{Interactive buckling of beams in bending}

Citation for published version (APA):

Menken, C. M., Groot, W. J., \& Stallenberg, G. A. J. (1991). Interactive buckling of beams in bending. ThinWalled Structures, 12(5), 415-434. https://doi.org/10.1016/0263-8231(91)90043-I

DOI:

10.1016/0263-8231(91)90043-I

Document status and date:

Published: 01/01/1991

\section{Document Version:}

Publisher's PDF, also known as Version of Record (includes final page, issue and volume numbers)

\section{Please check the document version of this publication:}

-A submitted manuscript is the version of the article upon submission and before peer-review. There can be important differences between the submitted version and the official published version of record. People interested in the research are advised to contact the author for the final version of the publication, or visit the $\mathrm{DOI}$ to the publisher's website.

- The final author version and the galley proof are versions of the publication after peer review.

- The final published version features the final layout of the paper including the volume, issue and page numbers.

Link to publication

\section{General rights}

Copyright and moral rights for the publications made accessible in the public portal are retained by the authors and/or other copyright owners and it is a condition of accessing publications that users recognise and abide by the legal requirements associated with these rights.

- Users may download and print one copy of any publication from the public portal for the purpose of private study or research.

- You may not further distribute the material or use it for any profit-making activity or commercial gain

- You may freely distribute the URL identifying the publication in the public portal.

If the publication is distributed under the terms of Article 25fa of the Dutch Copyright Act, indicated by the "Taverne" license above, please follow below link for the End User Agreement:

www.tue.nl/taverne

Take down policy

If you believe that this document breaches copyright please contact us at:

openaccess@tue.nl

providing details and we will investigate your claim. 


\title{
Interactive Buckling of Beams in Bending
}

\author{
C. M. Menken, W. J. Groot \& G. A. J. Stallenberg \\ Department of Mechanical Engineering, Eindhoven University of Technology, \\ Eindhoven. The Netherlands
}

(Received 11 October 1990; accepted 3 December 1990)

\begin{abstract}
A discrete model involving a limited number of degrees of freedom is presented. for analyzing the interaction between overall lateral-torsional buckling and local flange buckling, qualitatively. The results are compared with experiments and show a good qualitative agreement. The results suggest that a quantitative numerical analysis based on Koiter's asymptotic approach may have a wide range of validity.
\end{abstract}

\section{NOTATION}

$a$

$A_{\text {ij }}$

$A_{\text {ijk }}$

$A_{\text {ijk } 1}$

$b$

d

E

$h$

$k$

$l$

$P$

$P_{L}$

$P_{\mathrm{o}}$

Local buckling amplitude in the experiments Second order coefficients in $V$ Third order coefficients in $V$ Fourth order coefficients in $V$ Flange width Length of link Spring stiffness Web height Stiffness of precompressed spring Length Conservative load Critical load for local buckling Critical load for overall buckling

Thin-Walled Structures 0263-8231/91/\$03.50 1991 Elsevier Science Publishers Ltd. England. Printed in Great Britain 


$\begin{array}{ll}q_{2} & \text { Rotation representing incremental deflection } \\ Q_{1} & \text { Rotation representing torsion } \\ Q_{2} & \text { Rotation representing vertical deflection } \\ Q_{3} & \text { Rotation representing lateral deflection } \\ Q_{4} & \text { Shortening of original neutral axis } \\ Q_{5}, Q_{6} & \text { Local buckling amplitudes in the discrete model } \\ S_{1} & \text { Torsional stiffness } \\ u_{\mathrm{A}}, u_{\mathrm{B}}, u_{\mathrm{C}} & \text { Axial displacements } \\ u_{\mathrm{o}} & \text { Precompression of spring } \\ v & \text { Lateral deflection in experiments } \\ V & \text { Potential energy } \\ w & \text { Vertical deflection } \\ \lambda & \\ \phi & \text { Half wavelength of local buckle } \\ & \text { Midspan rotation in experiments }\end{array}$

\section{INTRODUCTION}

The detrimental effect that an interaction between local and overall buckling of structural members may have is well known.1.2 After recognizing its symptoms, this phenomenon was investigated thoroughly for structural members under uniform compression, including stiffened plates ${ }^{3}$ and shells, ${ }^{4}$ and thin-walled columns. ${ }^{5}$ The interaction between local buckling and lateral torsional buckling as a result of bending ${ }^{6}$ has been given less attention, but it is an area of practical importance, because thin-walled built-up girders are used extensively and the use of cold-formed and extruded members is increasing. Moreover, the wallthickness of extruded members is becoming thinner all the time.

This interaction problem was investigated in three different ways:

(1) By analyzing a simple discrete model that had only a few degrees of freedom, in order to learn more about this type of buckling.

(2) By performing interactive lateral-torsional buckling experiments, because little has been done on this subject. Some researchers even mention the scarcity of experiments..$^{7-9}$

(3) By developing a spline finite-strip computer program for simulating the interactive buckling behavior of prismatic beams with arbitrary cross-sections. ${ }^{10.11}$

The third way is based on the asymptotic approach described by Koiter: ${ }^{\text {? }}$ in fact, it only applies in the case of coincident or nearly coincident buckling loads. One of the aims of the experiments was to get a better 
insight into its range of applicability. Since the first two ways showed a remarkably good qualitative agreement, this paper reports some of the results obtained.

\section{THE DISCRETE MODEL}

It is a well-known fact that many buckling features can be simulated qualitatively by means of simple discrete models. Budiansky and Hutchinson ${ }^{13}$ presented a good example that illustrated the interaction between long wavelength (overall buckling) modes and short wavelength (local buckling) modes using a two-link model. Hunt and Williams ${ }^{14}$ investigated a slightly modified version in order to improve physical interpretability. This led the authors to simulate the interactive lateraltorsional buckling behavior of a T-section in bending with the model shown in Fig. 1. Attention was confined to a perfect model. The left-hand support allowed the model to rotate about its axis, counteracted by a torsional spring which simulated the torsional stiffness. The three linear springs, each having a stiffness of $E$, provided the model with vertical and lateral stiffness; however, in the flanges, each spring was in series with a precompressed spring. The precompression was achieved by means of the rigid links. The model was loaded at its right-hand end with a conservative load $P$. If this load increased, the spring link assembly would be compressed, which could equal the precompression in the

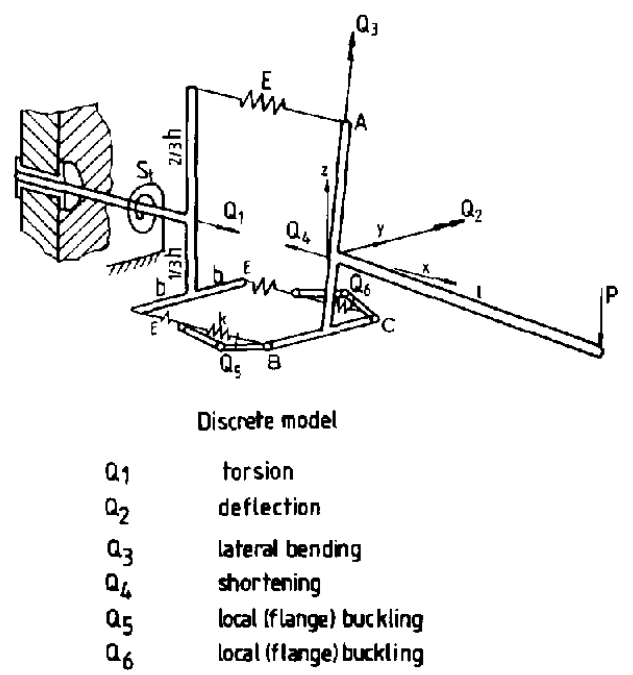

Fig. 1. The discrete model. 
springs and cause the links to buckle. The overall lateral-torsional buckling was characterized by the rotation $Q_{1}$ and the lateral bending $Q_{3}$. The angles $Q_{5}$ and $Q_{6}$ characterized the local buckling of the flanges, angle $Q_{2}$ being the vertical deflection of the beam, and displacement $Q_{4}$ being a shortening of the neutral axis similar to that caused by local buckling.

In order to make this model susceptible to lateral-torsional buckling. like a real beam, its parameters had to be chosen in such a way that:

(1) the lateral and torsional stiffnesses were much smaller than the vertical stiffness,

(2) the pre-buckling deflection could be neglected,

(3) the overall lateral-torsional buckling was neutral in the absence of local buckling,

(4) in the post-buckling region, the spring link assemblies behaved like a flat plate.

The exact potential energy expression, $V\left(Q_{1}, Q_{2}, Q_{3}, Q_{4}, Q_{5}, Q_{6}\right)$, was expanded in the displacements and truncated after the quartic terms. The incremental deflection $q_{2}$ and the shortening $Q_{4}$ would always be passive (dependent); consequently, they were eliminated. Since both $Q_{1}$ and $Q_{3}$ were non-zero components of the overall buckling mode, the authors chose $Q_{3}$ as the amplitude and treated $Q_{1}$ as the passive coordinate. After eliminating these coordinates, the potential energy expression looked like (see also the Appendix):

$$
\begin{aligned}
V\left(Q_{3}, Q_{5}, Q_{6}\right)= & \frac{1}{2} A_{33} Q_{3}^{2}+\frac{1}{2} A_{55} Q_{5}^{2}+\frac{1}{2} A_{66} Q_{6}^{2}+\frac{1}{2} A_{355} Q_{3} Q_{5}^{2} \\
& +\frac{1}{2} A_{366} Q_{3} Q_{6}^{2}+\frac{1}{24} A_{5555} Q_{5}^{4}+\frac{1}{4} A_{5566} Q_{5}^{2} Q_{6}^{2}+\frac{1}{24} A_{6666} Q_{6}^{4}
\end{aligned}
$$

where $A_{33}, A_{55}$ and $A_{66}$ are the buckling coefficients:

$$
\begin{aligned}
& A_{33}=\left(2 b^{2} E-\frac{P^{2} l^{2}}{S_{1}}\right) \\
& A_{55}=\left(P_{\mathrm{L}}-P\right) \frac{l d}{h}=A_{6 \hbar}
\end{aligned}
$$

The other coefficients are:

$$
\begin{aligned}
& A_{355}=2 b d E=-A_{366} \\
& A_{5555}=12 d^{2}\left(\frac{1}{2} E+k\right)=A_{\text {t6to6 }} \\
& A_{5566}=-2 d^{2} E
\end{aligned}
$$


As a result of the above-mentioned points (3) and (4), only the local buckling amplitudes $Q_{5}$ and $Q_{6}$ appeared up to and including the fourth order in the potential energy expression. This expression included the symmetry-breaking coefficients $A_{355}$ and $A_{366}$ that might cause destabilization in the post-buckling region. ${ }^{2}$

Finding the equilibrium paths from eqn (1) was not limited to coincident or nearly coincident buckling loads, like the continuous and discretized continuous models based on the asymptotic approach. ${ }^{3.5 .10}$ The authors focused on the situation where the local critical load $P_{1}$. was least: $A_{55}=A_{66}=0<A_{33}$. In this case, there would be three equilibrium paths:

- an uncoupled path, involving local buckling only:

$$
Q_{3}=0, \quad Q_{5}=Q_{6} \neq 0
$$

- two coupled paths, involving interactive buckling:

$$
\begin{array}{lll}
Q_{3} \neq 0, & Q_{5} \neq 0, & Q_{6}=0 \\
Q_{3} \neq 0, & Q_{5}=0, & Q_{6} \neq 0
\end{array}
$$

The two coupled paths are equivalent, due to the symmetry of the model. Now, we will confine ourselves to the path with $Q_{6}=0$, i.e. when the local buckling load has been reached, the overall buckling is triggered off in such a way that the pertinent lateral bending prevents the posterior 'flange' from buckling, while buckling of the anterior 'flange' is increased. For this case the potential energy expression becomes:

$$
V\left(Q_{3}, Q_{5}\right)=\frac{1}{2} A_{33} Q_{3}^{2}+\frac{1}{2} A_{55} Q_{5}^{2}+\frac{1}{2} A_{355} Q_{3} Q_{5}^{2}+\frac{1}{24} A_{5555} Q_{5}^{4}
$$

This is precisely the same expression as that for the so-called parabolic umbilic catastrophe which is a characteristic of many interactive buckling problems that have been analyzed by other investigators. Therefore, comparable behavior could be expected.

In order to decide whether path (2) or path (3) would be followed, we compared the respective potential energies in the vicinity of the bifurcation point for local buckling: $A_{55}=A_{66}=0$. Then the overall buckling amplitude $Q_{3}$ could also be eliminated from eqn (1), as it would be passive. From the requirement that $\partial V / \partial Q_{3}=0$, the following was obtained:

$$
Q_{3}=-\frac{A_{355}}{2} Q_{33}^{2}-\frac{A_{366}}{2 A_{33}} Q_{6}^{2}
$$


The respective potential energies became:

- in the case of local buckling alone:

$$
V\left(Q_{5}\right)=\frac{1}{12}\left(A_{5555}+3 A_{5566}\right) Q_{5}^{4}
$$

- in the case of interactive buckling:

$$
V\left(Q_{5}\right)=\frac{1}{24}\left(A_{5555}-3 \frac{A_{355^{2}}}{A_{33}}\right) Q_{5}^{4}
$$

For this model, $A_{5555}=18 E d^{2} . A_{55 \% 6}=-2 E d^{2}$ and the buckling coefficient $A_{33}$ is positive as long as the load is smaller than the overall buckling load. Therefore, it follows that interactive buckling will minimize the potential energy more than local buckling alone. Thus, interactive buckling will dominate. In Section 4, figures of the equilibrium paths are presented diagrammatically. In the calculations, the authors chose $h=9 b$.

\section{INTERACTIVE BUCKLING EXPERIMENTS}

In the experiments, a simply supported prismatic T-beam was loaded in pure bending (Fig. 2) in such a way that, as with the discrete model, the flanges were in compression. The beam was built up from a thin flange, carefully machined from sheet metal and glued to a relatively stiff web (Fig. 3).

In the authors opinion. this was a good way of providing the flange with a practically uniform thickness. It was verified experimentally that the glue had no influence on the bending stiffness. The material was aluminium. The variables measured were:

- the overall buckling components that were the lateral displacement, $v$, of the centre of gravity of the cross-section, and the rotation. $\phi$. of the relatively stiff web; as well as:

- the amplitude, $a$, and half the wavelength. $\lambda$, of the local buckles.

Figure 4 shows the main features of the test rig. The beam was simply supported by suspending it from two thin strips; its in-plane rigidity

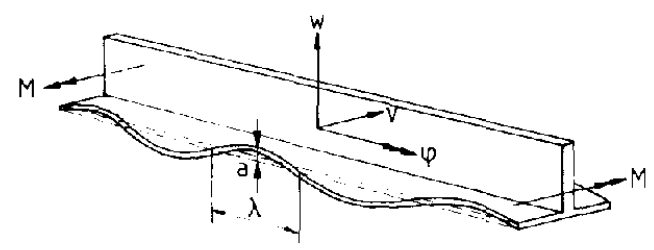

Fig. 2. The T-beam as used in the experiments. 


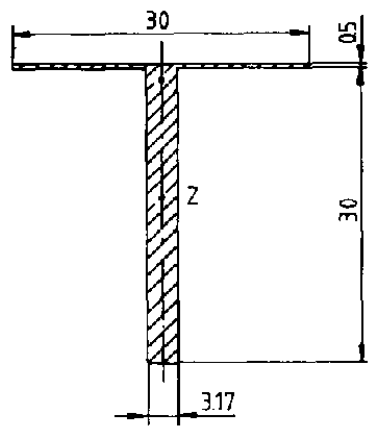

Fig. 3. Cross-section of the test specimen.

prevented both vertical displacement at the ends and rotation about the longitudinal axes. On the other hand, the bending and torsional flexibility of the strips permitted the ends of the beam to rotate freely with respect of their principal axes. This design was based on the earlier lateraltorsional buckling experiments of Cherry. ${ }^{15}$ Mounting a test specimen in the test rig posed a particular problem, because twisting of the beam might occur. Therefore, a cylindrical boss made of Araldit was fixed to each end. Each boss was inserted into the holder attached to one of the

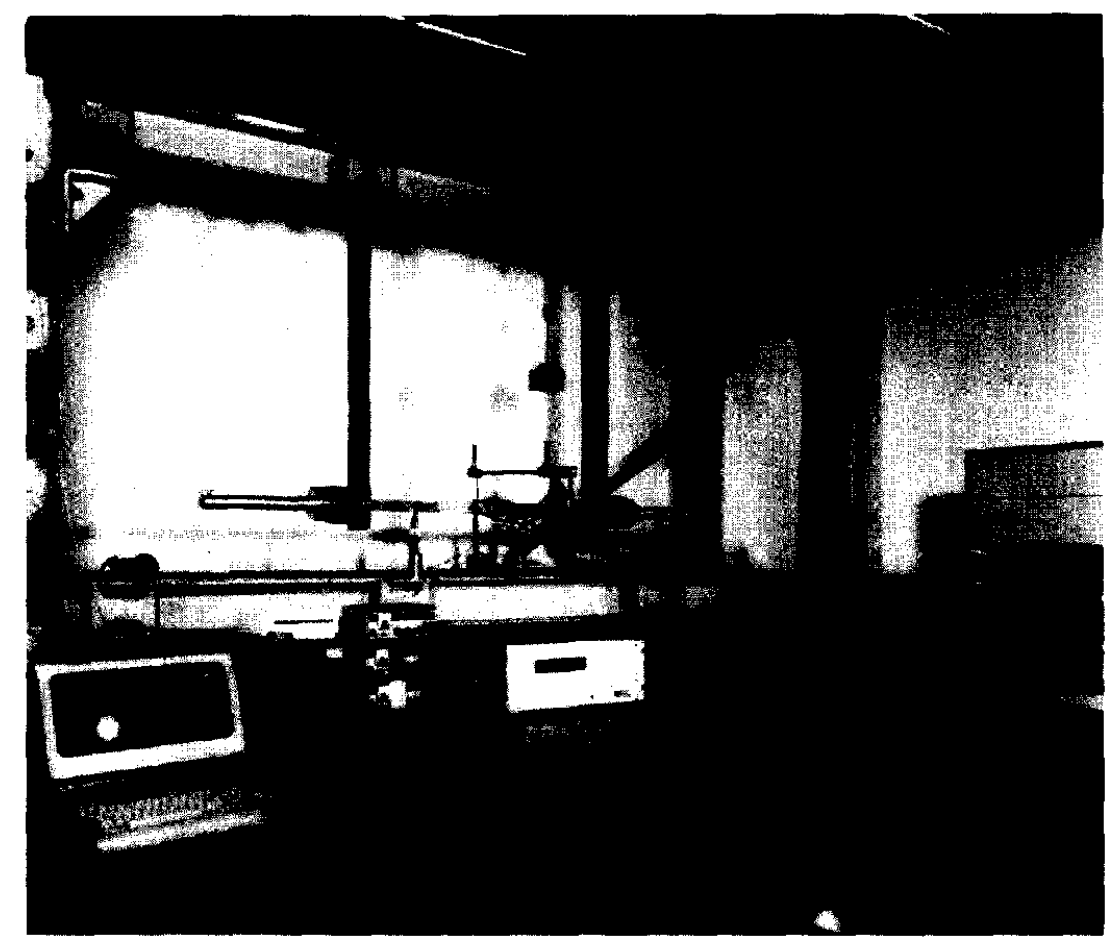

Fig. 4. The test rig. 
suspension strips. The jaws of the holder were tightened by turning a tapered nut. A lever was attached to each nut in order to apply the bending moment. A simple dead-loading device was used, the consequence being that descending equilibrium paths could not be followed during the experiments. Lateral deflections of the specimen were prevented from becoming too large by means of a hold-up.

The overall buckling components were determined by measuring the lateral deflections of two points on the web midspan of the beam. The average gave the lateral deflection, whereas the difference between them was a measure for the rotation of the cross-section. The elements of local buckling were measured by four light-weight displacement transducers attached to the relatively stiff web (see Fig. 5). From the four displacements measured, it was possible to determine:

- the amplitude of the local buckle.

- half the wavelength of the local buckle,

- the phase shift,

- the average transverse displacement of the edge of the flange, e.g. caused by the Poisson effect.

Figure 6 shows an example of local buckling alone, it could be obtained only by preventing lateral bending of the beam. This confirmed the authors' theory that interactive buckling would dominate over exclusive local buckling. When the beam was free to deflect laterally, interactive

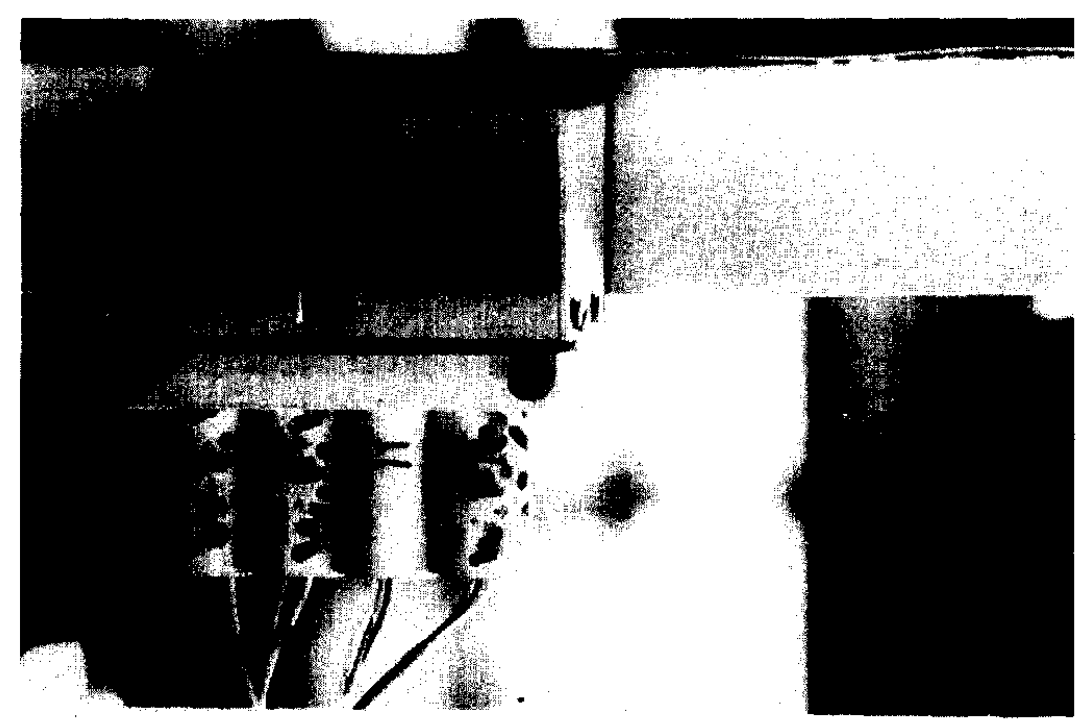

Fig. 5. Displacement transducers for measuring the properties of the local buckles. 


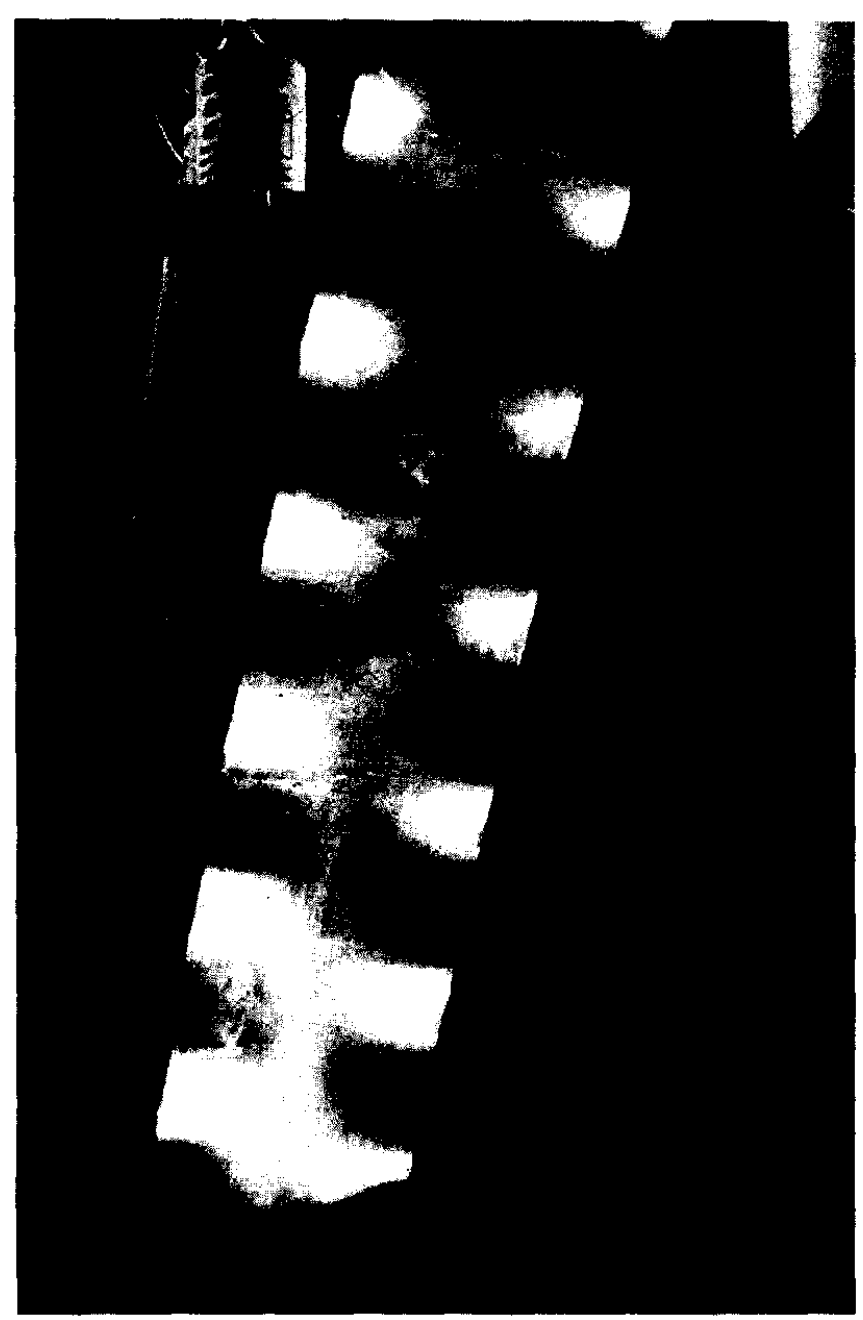

Fig. 6. Local buckling alone.

buckling would occur. Figure 7 shows a good example of overall buckling and local flange buckling in combination.

\section{A QUALITATIVE COMPARISON OF THEORETICAL AND EXPERIMENTAL RESULTS}

In both the discrete model and the experiment, the prime variable was the ratio of the overall buckling load to the local buckling load. In the discrete model, the overall buckling load was constant, whereas the local 


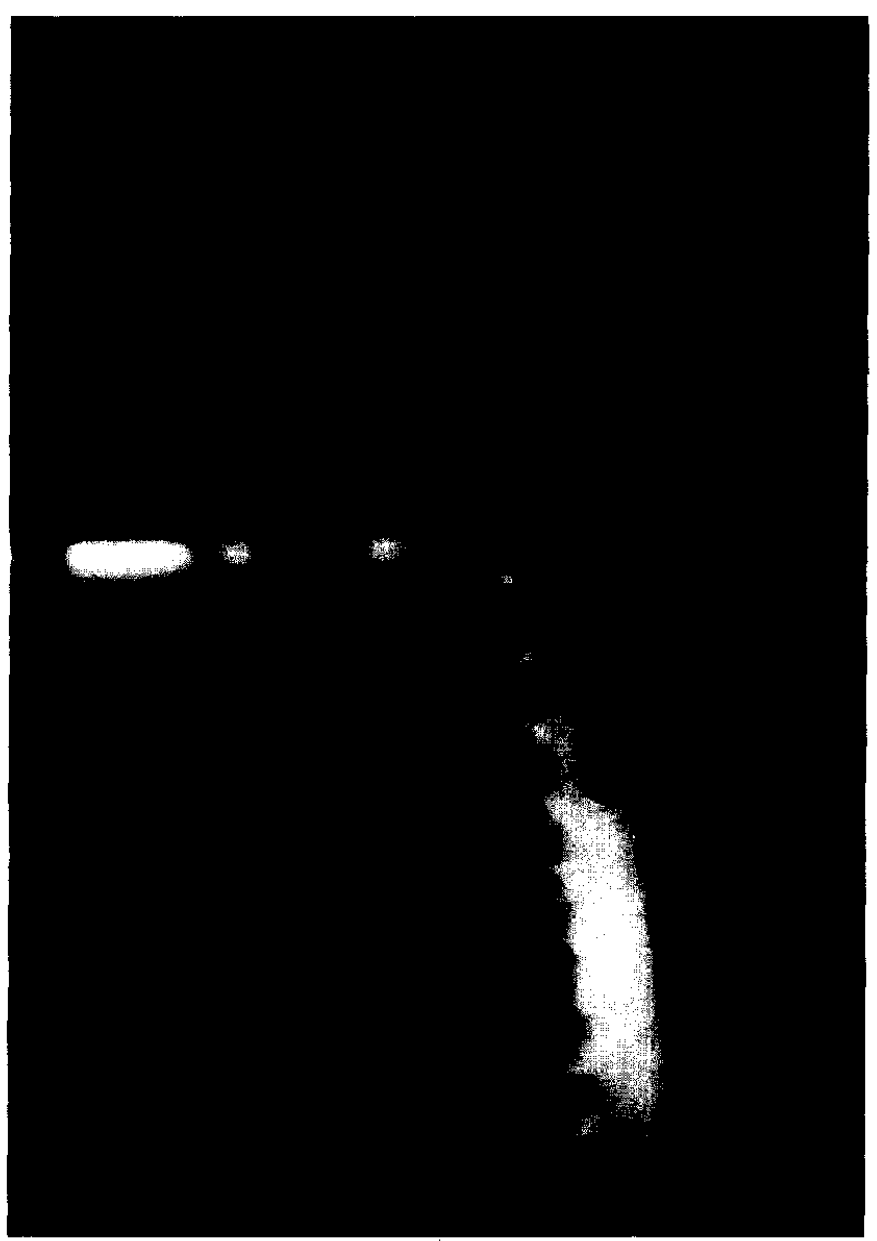

Fig. 7. Overall buckling and local buckling in combination.

buckling load could be varied by changing the precompression of the relevant springs. In the experiments, the local buckling load was constant, the cross-sectional dimensions being fixed, but the overall buckling load was altered by changing the length of the beam.

Figure 8 shows the overall buckling amplitude versus a dimensionless load, as obtained from the discrete model. When the overall buckling load is much greater than the local buckling load. the value of the buckling coefficient $A_{33}$ (eqn (8)) still prevents excessive reduction of the post-buckling stability, so that the equilibrium paths rise, whilst they descend when the critical loads approach each other. Figure 9 shows the comparable results from the experiments. The parameters marked on the curves are the lengths of the beams. For a short beam, the overall 


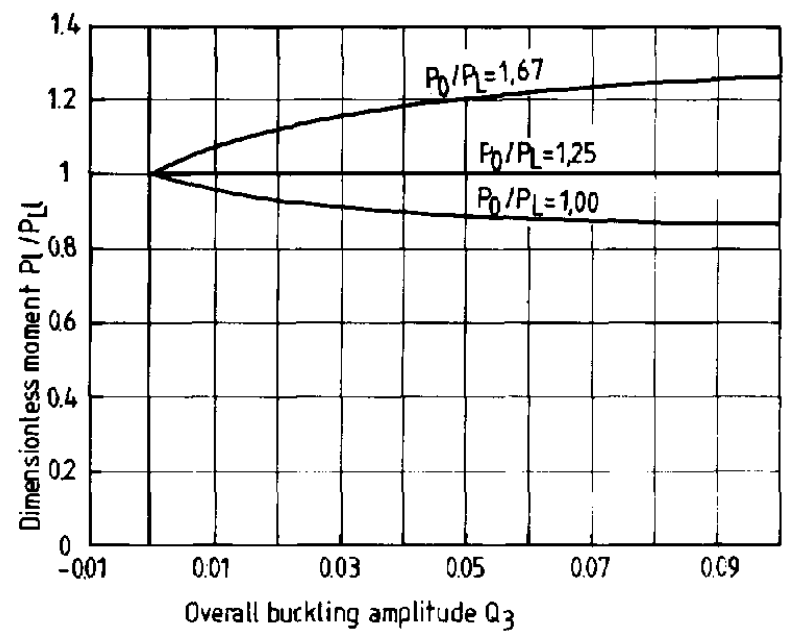

Fig. 8. Discrete model: overall buckling amplitude versus dimensionless load.

buckling load was much greater than the local buckling load. When the length of the beam increased, the critical loads approached each other and, as with the discrete model, the slope of the equilibrium paths decreased. The beam with a length of $1250 \mathrm{~mm}$ showed snap-through buckling, due to an imperfection, the dead-loading and the buckling loads almost coinciding. At a beam length of $1500 \mathrm{~mm}$, the overall buckling was smallest and the post-buckling behavior was stable again.

With regard to the local buckling behavior. Fig. 10 shows the local buckling amplitude versus a dimensionless load for the discrete model. If the critical load for lateral-torsional buckling is much greater than the local buckling load, a plate-like stable symmetric bifurcation will

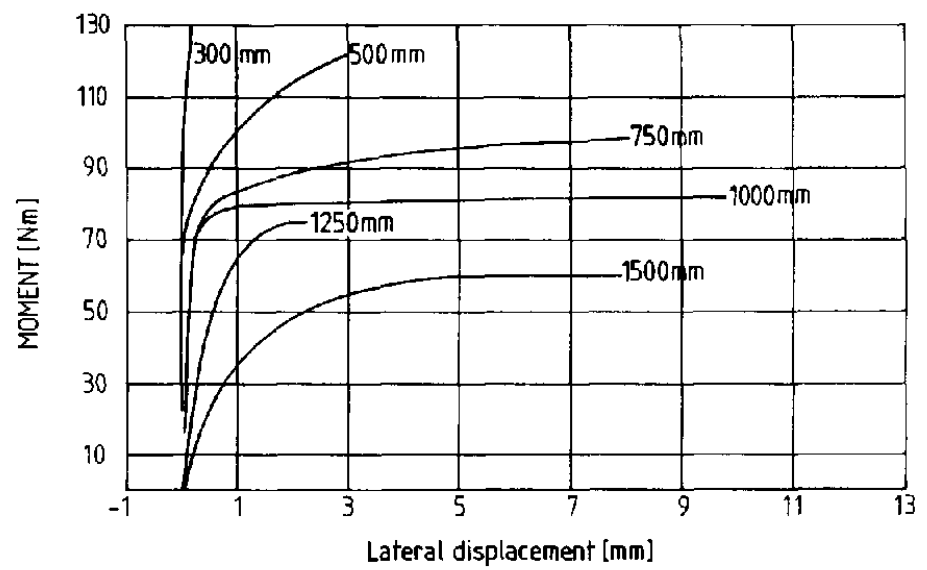

Fig. 9. Experiments: overall buckling amplitude versus dimensionless load. 


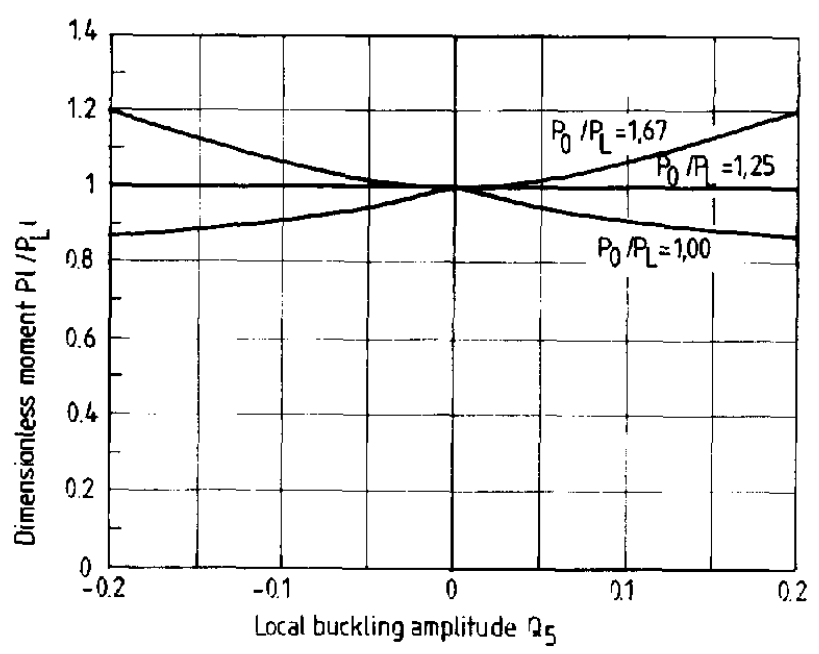

Fig. 10. Discrete model: local buckling amplitude versus dimensionless load.

dominate. When the buckling loads approach each other, the slope of the post-buckling equilibrium path decreases. The comparable results obtained from the experiment are shown in Fig. 11.

For the shortest beam, the distance between the overall and local buckling loads is greatest and, again, the plate-like stable post-buckling behavior is apparent. While most equilibrium paths show a rather smooth transition from the unbuckled to the buckled state (which can be ascribed to imperfections), the local buckle in the longest beam $(1500 \mathrm{~mm})$ appears rather suddenly. In this case, overall buckling precedes local buckling, the latter being caused by a secondary bifurcation.

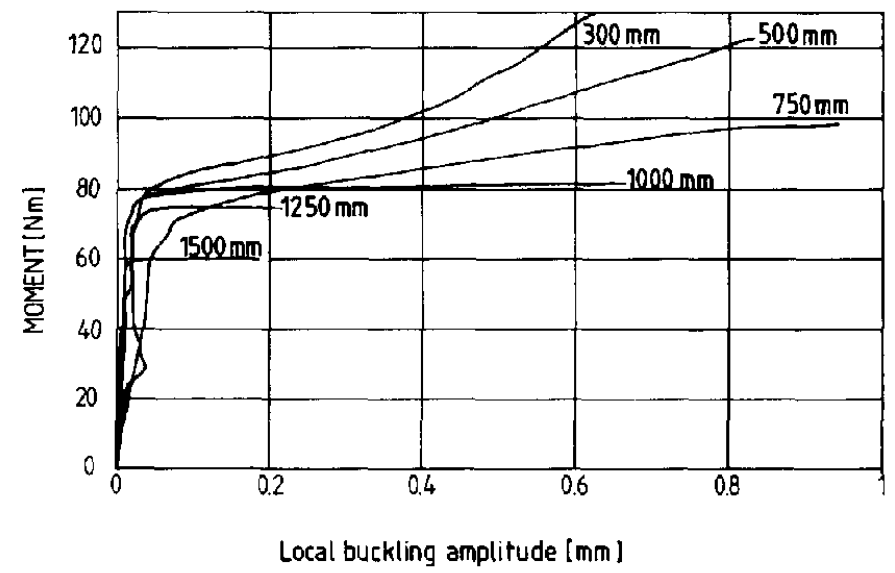

Fig. 11. Experiments: local buckling amplitude versus dimensionless load. 
Figure 12 shows the relationship between the amplitudes of local and overall buckling. As long as the local buckling load is the smaller, the equilibrium paths have a vertical tangent at the origin, indicating that, in the limiting case of vanishing displacements, only the local buckling mode occurs. In the post-buckling region, however, the overall component appears progressively (see eqn (6)). Figure 13 shows the relationship between the local and overall buckling amplitudes that was obtained experimentally. For a very short beam, local buckling dominated, but the equilibrium path was not entirely free of lateral deflection, which confirms that there is always some interaction between them. The broken lines connect the last equilibrium point that was

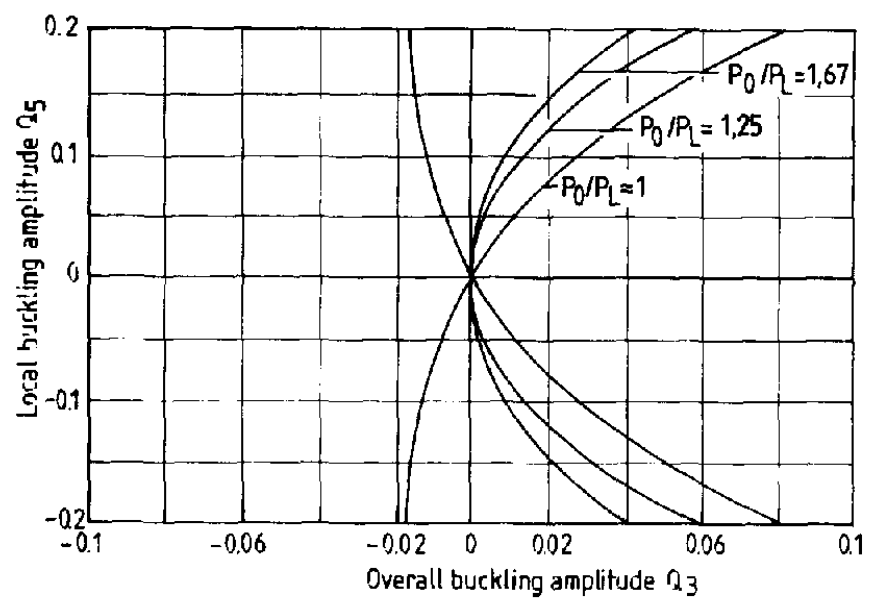

Fig. 12. Discrete model: relationship between the amplitudes of local and overall buckling.

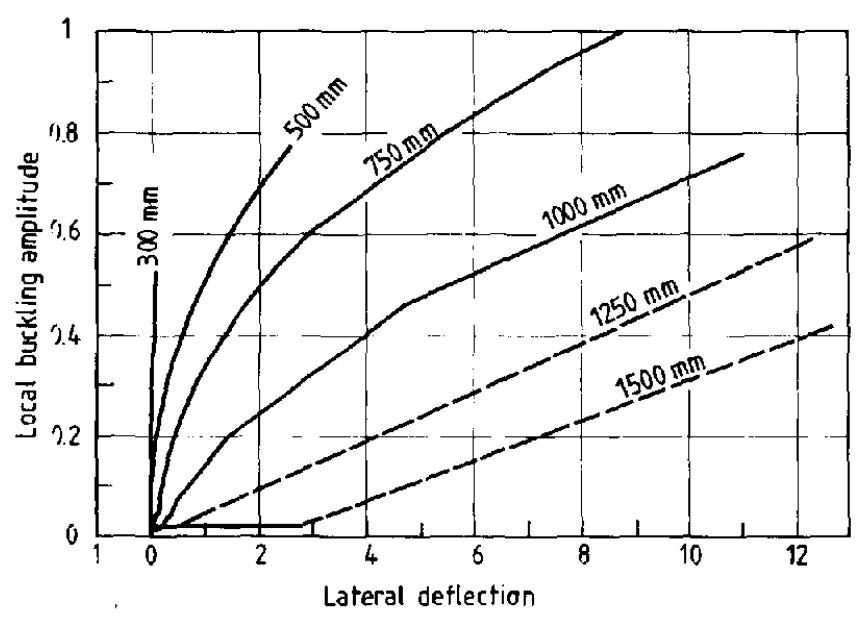

Fig. 13. Experiments: relationship between the amplitudes of local and overall buckling. 
observed while increasing the load, with the equilibrium point pertaining to the situation where buckling was arrested by the hold-up and, thus, indicates snap-through.

Figure 14 shows the relationship between the two displacements of the overall buckling mode. Strictly speaking, the buckling mode only refers to vanishing displacements at the critical load. The figure shows, however, that an overall mode is roughly maintained even though overall buckling is relegated to the post-buckling range, and the displacements are finite. If we compare the relationship between $Q_{1}$ and $Q_{3}$ (see eqn (A11)) with the buckling mode (see eqn (A10)), it can be seen that they are nearly the same, provided that the load remains in the

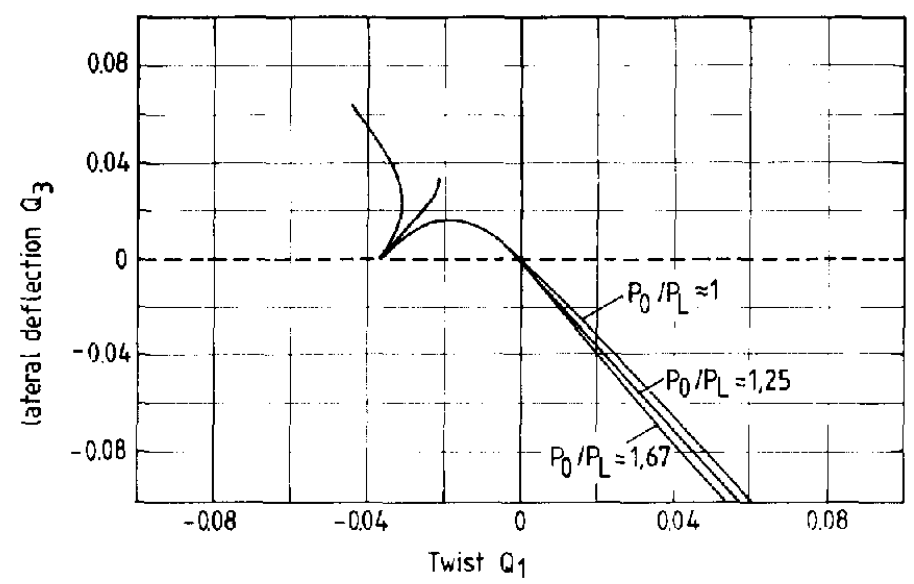

Fig. 14. Discrete model: relationship between the displacements of the overall buckling mode.

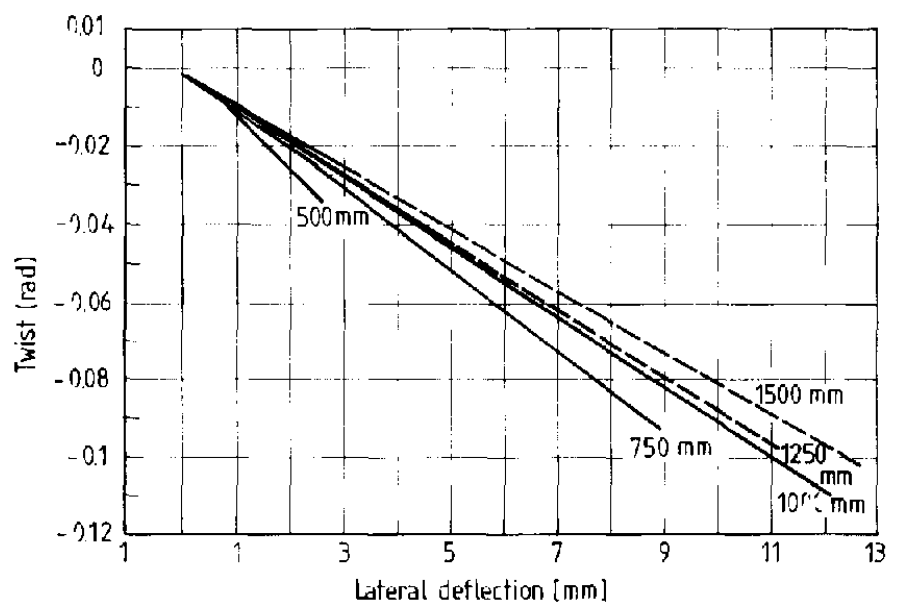

Fig. 15. Experiments: relationship between the displacements of the overall buckling mode. 
vicinity of the overall buckling loads. The experiments shown in Fig. 15 confirm this behavior.

\section{CONCLUSIONS}

From an analysis of the simple discrete model, and from the preliminary experiments, it can be concluded that:

- interactive lateral-torsional buckling belongs to the class of parabolic umbilic catastrophes, according to the discrete model studied;

- there is a good qualitative agreement between the results obtained from the discrete model and those obtained from the experiments;

- theoretically, interactive buckling will always occur when the local buckling load is smaller than the overall buckling load;

- both the shape of the equilibrium paths in the post-buckling region and the continuation of a buckling mode at finite deflections suggest that the asymptotic approach to the analysis of buckling behavior may have a relatively wide range of applications for interactive lateral-torsional buckling.

\section{ACKNOWLEDGEMENT}

This work was supported by research grants from The Netherlands Technology Foundation (STW).

\section{REFERENCES}

1. Neut. A. van der, The interaction of local buckling and column failure of thin-walled compression members. Proc. 12th Int. Congr. Theor. and Appl. Mech., Springer Verlag, Berlin, 1969, pp. 389-99.

2. Thompson, J. M. T. \& Hunt, G. W.. Elastic Instability Phenomena, John Wiley and Sons, Chichester, 1984.

3. Koiter, W. T. \& Pignataro, M., A general theory for the interaction between local and overall buckling of stiffened panels. Delft University of Technology, Report WTHD-83, 1976.

4. Byskov, E. \& Hutchinson, J. W.. Mode interaction in axially stiffened cylindrical shells. AIAA Journal, 15(7) (1977) 941-8.

5. Sridharan, S. \& Ali, M. A., An improved interactive buckling analysis of thin-walled columns having doubly symmetric sections. Int. Journal of Solids and Structure, 22(4) (1987) 429-43.

6. Mollmann, H. \& Goltermann, P.. Interactive buckling in thin-walled beams. Int. J. Solids and Structures, 25(7) (1989) 715-49. 
7. Davies, J. M. \& Thomasson, P. O., Local and overall buckling of light gage members. In Instability and Plastic Collapse of Steel Structures, ed. L. J. Morris. Granada Publishing, London, 1983, pp. 479-92.

8. Benito, R., Static and dynamic buckling of plate assemblies. Thesis submitted in partial fulfillment of the requirements of DSc degree of the Washington University of St. Louis, 1983.

9. Sridharan, S. \& Benito, R., Static and dynamic interactive buckling. Journal of Engng. Mech., ASCE, 110 (1) (1984) 49-65.

10. Erp, G. M. van, Advanced buckling analysis of beams with arbitrary cross sections. PhD Thesis, Eindhoven University of Technology, May 1989.

11. Erp, G. M. van \& Menken, C. M., The spline finite strip method in the buckling analysis of thin-walled structures. Communications in Applied Numerical Methods, 6(6) (1990) 477-84.

12. Koiter, W. T. Elastic stability and post buckling behaviour. In Nonlinear Problems, ed. R. E. Langer, University of Wisconsin Press, Madison. WI, 1963.

13. Budiansky. B. \& Hutchinson, J. W., Buckling: progress and challenge. In Trends in Solid Mechanics. Proceedings of the symposium dedicated to the 65th birthday of W. T. Koiter. Delft University Press, Delft, 1979, 93-116.

14. Hunt. G. W. \& Williams, K. A. J., Closed form and asymptotic solutions for an interactive buckling model. J. Mech. Phys. Solids, 32(4) (1984) 101-18.

15. Cherry. S., The stability of beams with buckled compression flanges. Structural Engineer, 38(9) (1960) 277-85.

\section{APPENDIX}

\section{The potential energy of the discrete model}

The model is composed of linear elastic springs, together with rigid links and bars. It was assumed that during deformation all springs remained parallel to the original axis of the beam. The overall lateral-torsional buckling and vertical deflection are represented by the rotations, $Q_{1}, Q_{3}$ and $Q_{2}$, respectively. Local buckling may cause a shortening of the original neutral axis, $Q_{4}$. The compression of the spring simulating the web behavior, $u_{\mathrm{A}}$. and the displacements of the spring-link assemblies simulating the flange behavior, $u_{\mathrm{B}}$ and $u_{\mathrm{C}}$, are expressed in the overall rotations. The authors used a description in Euler angles to obtain these expressions, the rotation vector $Q_{3}$ remaining along $O A$ and the sequence of rotations being $Q_{2}, Q_{3}, Q_{1}$. The right-hand displacements of the springs are:

$$
\begin{aligned}
& u_{\mathrm{A}}=Q_{4}-2 a \sin Q_{2} \\
& u_{\mathrm{B}}=Q_{4}+a \sin Q_{2}-b \cos Q_{2} \sin Q_{3} \\
& u_{\mathrm{C}}=Q_{4}+a \sin Q_{2}+b \cos Q_{2} \sin Q_{3}
\end{aligned}
$$


The displacement of the vertical load is:

$u_{\mathrm{p}}=l\left(\cos Q_{1} \cos Q_{3} \sin Q_{2}-\sin Q_{1} \sin Q_{3}\right)$

Local (flange) buckling is simulated by means of spring-link assemblies. The springs having a stiffness of $k$ are precompressed over a distance $u_{0}$ by means of the links. If the external load causes a compression smaller than $u_{0}$, the stiffness of each assembly will remain $E$. However, if the compression exceeds the precompression, the links will buckle and the springs become in series, so that a smaller overall stiffness is produced.

The local buckling is represented by $Q_{5}$ and $Q_{6}$. If local buckling occurs, the full compression of the precompressed springs becomes:

$$
u_{\mathrm{k}}=u_{0}+2 d\left(1-\cos Q_{\mathrm{i}}\right) \text { with } i=5,6
$$

In this case, the compression of the springs having a stiffness $E$ will become:

$$
\begin{aligned}
& u_{\mathrm{EB}}=u_{\mathrm{B}}-2 d\left(1-\cos Q_{5}\right) \\
& u_{\mathrm{EC}}=u_{\mathrm{C}}-2 d\left(1-\cos Q_{6}\right)
\end{aligned}
$$

The expression for the potential energy now becomes:

$$
\begin{aligned}
& V\left(Q_{1}, Q_{2}, Q_{3}, Q_{4}, Q_{5}, Q_{6}\right)=\frac{1}{2} S t Q_{1}^{2}+\frac{1}{2} E u_{\mathrm{A}}^{2} \\
& \quad+\frac{1}{2} E\left\{u_{\mathrm{B}}-2 d\left(1-\cos Q_{5}\right)\right\}^{2}+\frac{1}{2} E\left\{u_{\mathrm{C}}-2 d\left(1-\cos Q_{6}\right)\right\}^{2} \\
& +\frac{1}{2} k u_{\mathrm{kB}}^{2}+\frac{1}{2} k u_{\mathrm{kC}}^{2}-P u_{\mathrm{p}}
\end{aligned}
$$

\section{Expansion of the potential energy expression around the fundamental state}

The fundamental state is represented by the deflection $Q_{2}=Q_{2}^{\mathrm{F}}$. The authors assumed a linear elastic behavior prior to buckling: $Q_{2}^{\Gamma} \ll 1$. The relevant potential energy expression is:

$$
V\left(Q_{2}^{\mathrm{F}}\right)=\frac{1}{2} \cdot 6 a^{2} E\left(Q_{2}^{\mathrm{F}}\right)^{2}+\frac{1}{2} \cdot 2 k u_{0}^{2}-P l Q_{2}^{\mathrm{F}}
$$

Stationarity with respect to $Q_{2}^{\mathrm{F}}$ gives the fundamental path:

$$
Q_{2}^{\mathrm{F}}=\frac{P l}{\frac{2}{3} h^{2} E}
$$

The potential energy increment, caused by displacements relative to the fundamental path, can be obtained from eqn (A1) by splitting $Q_{2}$ into:

$$
Q_{2}=Q_{2}^{\mathrm{F}}+q_{2}
$$


where $q_{2}$ represents the incremental vertical deflection. The following assumptions are made:

- the cross-section is slender: $b^{2} \ll h^{2}$

- the incremental deflection is very small: $q_{2} \ll 1$

- the wavelength of the local buckle is of the same order of magnitude as the flange width:

$d=0(b)$

- the precompression of the relevant springs is relatively small:

$u_{0} \ll d$

- the additional compression of these springs is of the same order of magnitude as the displacements of the flange tips:

$$
d Q_{5}^{2}=0\left(b Q_{3}\right) \text { and } d Q_{6}^{2}=0\left(b Q_{3}\right)
$$

From eqns (A3) and (A6), it appears that:

$$
\begin{aligned}
& b d Q_{3} Q_{5}^{2} \ll h^{2} \\
& b d Q_{3} Q_{6}^{2} \ll h^{2}
\end{aligned}
$$

Successively, the trigonometric terms can be expanded about the fundamental state, the potential energy of the fundamental state is subtracted, and the aforementioned assumptions and the equilibrium equation for the fundamental state are utilized.

The resulting fourth order potential energy expression is:

$$
\begin{aligned}
& V\left(Q_{1}, q_{2}, Q_{3}, Q_{4}, Q_{5}, Q_{6}\right)=\frac{1}{2} S t Q_{1}^{2}+\frac{1}{3} h^{2} E q_{2}^{2}+b^{2} E Q_{3}^{2}+\frac{1}{3} b^{2} E Q_{3}^{4} \\
& \quad+\frac{1}{3} E Q_{4}^{2}-a d E\left(Q_{5}^{2}+Q_{6}^{2}\right)\left(\frac{P l}{\frac{2}{3}}-q_{2}^{2} E\right. \\
& \quad+b d E\left(Q_{5}^{2}-Q_{6}^{2}\right) Q_{3}-d E\left(Q_{5}^{2}+Q_{6}^{2}\right) Q_{4}+k u_{0} d\left(Q_{5}^{2}+Q_{6}^{2}\right) \\
& \quad+\frac{1}{2} d^{2}(E+k)\left(Q_{5}^{4}+Q_{6}^{4}\right)+P I Q_{1} Q_{3}
\end{aligned}
$$

\section{The critical loads}

The critical loads can be obtained by making the quadratic part of the potential energy stationary. This results in the following stability matrix: 


$\left[\begin{array}{cccccc}S_{1} & 0 & P l & 0 & 0 & 0 \\ 0 & \frac{2}{3} h^{2} E & 0 & 0 & 0 & 0 \\ P l & 0 & 2 b^{2} E & 0 & 0 & 0 \\ 0 & 0 & 0 & 3 E & 0 & 0 \\ 0 & 0 & 0 & 0 & 2 k u_{0}-\frac{P l}{h} & 0 \\ 0 & 0 & 0 & 0 & 0 & 2 k u_{0}-\frac{P l}{h}\end{array}\right]\left[\begin{array}{c}Q_{1} \\ q_{2} \\ Q_{3} \\ Q_{4} \\ Q_{5} \\ Q_{6}\end{array}\right]=\left[\begin{array}{l}0 \\ 0 \\ 0 \\ 0 \\ 0 \\ 0\end{array}\right]$

This gives the overall buckling load:

$$
P_{0}=\frac{b}{l} \sqrt{2 E S_{\mathrm{t}}}
$$

together with two identical local buckling loads of magnitude:

$$
P_{\mathrm{L}}=\frac{2 k u_{0} h}{l}
$$

The overall buckling mode contains two non-zero parameters, $Q_{1}$ and $Q_{3}$, where the relationship between them is:

$$
Q_{1}=-\frac{P_{0} l}{S_{\mathrm{t}}} Q_{3}
$$

\section{Adaptation of the model and confirmation of some assumptions}

Since the post-buckling stiffness of flat plates is about half the original stiffness, depending on the boundary conditions, the discrete model has been adapted to it by taking $k=E$. If the critical loads are available (see eqns (A8) and (A9)) the magnitude of the pre-buckling deflection can be checked when the overall buckling load is attained:

$$
\left(Q_{2}^{\mathrm{F}}\right)_{P=P_{11}}=\sqrt{\frac{\left(2 b^{2} E\right) S_{1}}{\left(\frac{2}{3} h^{2} E\right)^{2}}}
$$

Since both the lateral stiffness $\left(2 b^{2} E\right)$ and the torsional stiffness $\left(S_{t}\right)$ are assumed to be small when compared with the vertical stiffness $\left(\frac{2}{3} h^{2} E\right)$, the pre-buckling deflection is indeed small. The pre-buckling deflection at the local critical load is:

$$
\left(Q_{2}^{F}\right)_{P=P_{1}}=\frac{3 u_{0}}{h}
$$


and since the precompression $u_{0}$ is assumed to be small, this prebuckling deflection will also be small.

The fact that a plate-like post-buckling behavior of the flanges has been combined with a nearly neutral overall post-buckling behavior, implies that the former will be dominant. In this case, the $Q_{3}^{4}$-term in the potential energy eqn (A7) can be omitted.

\section{Elimination of passive coordinates}

Inspecting the stability matrix shows that there are at least three passive coordinates. ${ }^{2}$ They are: the incremental deflection, $q_{2}$, the shortening, $Q_{4}$ and one of the parameters of the overall buckling mode. The authors have chosen $Q_{1}$ as the passive coordinate, leaving $Q_{3}$ as the amplitude of the overall buckling mode. From the stationarity of the potential energy, the following is obtained:

$$
\begin{aligned}
& \partial v / \partial Q_{1}=0 \rightarrow Q_{1}=-\frac{P l}{S t} Q_{3} \\
& \partial v / \partial Q_{2}=0 \rightarrow q_{2}=-\frac{d}{6 a}\left(Q_{5}^{2}+Q_{6}^{2}\right) \\
& \partial v / \partial Q_{4}=0 \rightarrow Q_{4}=\frac{d}{3}\left(Q_{5}^{2}+Q_{6}^{2}\right)
\end{aligned}
$$

It can be seen that only local buckling can give rise to increments in the deflection and shortening. 